\title{
An Experimental Study of Sensor-less Fault Diagnosis on Rolling Bearing of Wind Turbine Generator System
}

\author{
Xianjiang $\mathrm{SHI}^{\mathrm{a}}$, Jiankun $\mathrm{ZHANG}^{\mathrm{b}}$, Heng $\mathrm{DU}^{\mathrm{c}}$, Jingchun $\mathrm{ZHANG}{ }^{\mathrm{d}}$ \\ Mechanical \& Power Engineering College, Harbin University of Science and Technology ,Harbin, \\ 150080,China \\ aemail: hustsxj@hrbust.edu.cn, bemail: zjkzza@126.com, 'email: duheng1228@126.com, \\ demail: jingchunbulibuqi@163.com
}

Keywords: Rolling Bearing; Fault Diagnosis; Sensor-less Detect; Wind Turbine Generator

\begin{abstract}
This paper study sensor-less fault diagnosis on rolling bearing of wind turbine generator system, by means of establishing an experiment that can simulate doubly fed wind power generation system, on basis of the mathematical model that reflects magnetic flux density impacts on the electrical signal, using the method of Motor Current Signature Analysis. According to collect the electrical signal and shaft's made by the generator bearing that works in normal and fault condition, analyzing the fault principle for the bearing of the transmission chain and the fault signal's feature. The experiment results show that the stator current signal's feature is familiar with the predicted failure frequency and the characteristic frequency of the main shaft frequency signal When rolling bearing fails, and provide the detecting sensor-less method of rolling bearing wind generator fault detection and diagnosis is feasible as well.
\end{abstract}

\section{Introduction}

Wind power as an environmentally energy technology has been concerned around the world, but the wind power system is usually installed in remote areas. At the same time, installation and maintenance of the detection sensors are so difficult that it is hard to do the task of the assembling unit's detection and diagnosis. Therefore, a simple and effective fault monitoring and diagnosis methods is necessary to reduce losses and protect the long-term stable and reliable of the wind turbine operation.

Rolling bearings in wind turbine system belongs to the multiple fault location, considering the generator and bearing characteristics of wind power system when it is at runtime, the fault information will be coupled to the electric circuit of the AC generator when the failure of bearing emerges. A method based on Motor Current Signature Analysis [1] get the attention of scholars both at home and abroad in recent years. It avoids the usual vibration detection sensors installed directly on the system equipment, using only current, voltage sensor, consider the motor stator current signal as a starting point to study the correspondence between their spectrum characteristics and faults. Many domestic and overseas scholars theoretical has done a lot of analysis and experimental about this problem[2-4]. The advantage of this method is that it overcomes the difficulty during the vibration signal acquisition, because of it can collect the information from the Current and Voltage Transmitter which be installed intensively in Substation for remote fault diagnosis. It's certain to contribute to reducing the cost of detection and maintenance and ensuring the normal operation of the wind power system.

In the paper, a special test-bed was set up under laboratory conditions. According to analyze the electrical signal and shaft's made by the generator bearing that works in normal and fault condition, discussed the possibility of the motor stator current signal analysis for rolling bearing fault detection from another perspective. 


\section{Rationale for the fault diagnosing of rolling bearing}

The stator current detection theory based on the electromagnetic torque. Such as the fault model shown in figure 1, When it's functioning normally, the load torque of the bearing $T_{L}$ is equal to the motor electromagnetic torque $T_{e}$; If a fault occurs, when the ball pass through the inner race and outside race, it will produce an additional torque $T_{L F}$, correspondingly a stator coil in the motor would give the additional current component, generates a corresponding additional torque $T_{e F}$ to balance $T_{L F}$. Additional current in the motor stator should be modulated on the power supply frequency $f_{s}$, so there are:

$$
f_{\text {Tf }}=\left|f_{s}+k f_{c}\right|
$$

Where $f_{\mathrm{c}}$ is also one of the characteristic vibrational frequencies, $k=1,2,3, \cdots$.

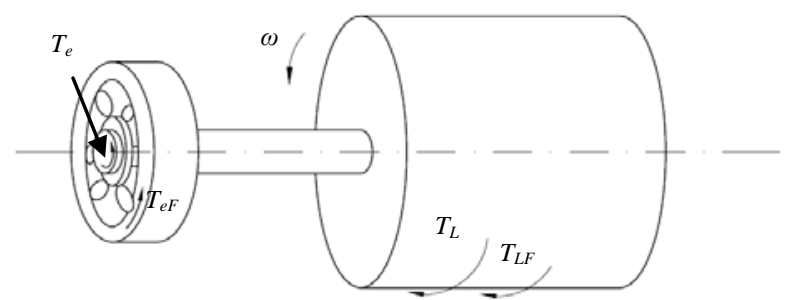

Fig.1 Rolling bearing failure cause additional rotor electromagnetic torque

According to a mathematical model of the bearing fault detection based on stator current proposed by Martin Blod [5], the fluctuations of rotor electromagnetic torque can cause the extra Time-Varying magnetic flux, extra magnetic flux density caused by extra Time-Varying magnetic flux makes the current signal produces the other frequency components. The equation of stator voltage is:

$$
V_{m}(t)=R_{s} I_{m}(t)+\frac{d \Phi_{m}(t)}{d t}
$$

The instantaneous frequency $(\varphi(t))$ of a signal is it's phase derivation of time, the frequency of stator current related to the defective part is:

$$
f(t)=\frac{1}{2 \pi} \frac{d \varphi(t)}{d t}=f_{s}-p A_{c} f_{c} \sin \left(\omega_{c} t\right) \pm k f_{c}
$$

Where $k=0$ or 1 , torque changes, therefore, the effect of the change of the electric current is the phase modulation of electrical signals, phase modulation is equivalent to the process of changing with time and frequency.

\section{Rolling Bearing Fault of Wind Turbine Generator System Simulation Experiment Device}

The simulation experiment of physical specific form is shown in figure 2.The fan impeller simulation using $5.5 \mathrm{~kW}$ AC asynchronous motor, by adjusting the frequency converter to simulate the changing wind field. It adopts $1.5 \mathrm{~kW}$ three-phase asynchronous motor as a doubly-fed induction generator. The inverter supply power for the rotor, it is used to simulate doubly-fed generator running state. Impedance loads connect to the generator stator winding. Gearbox with planetary gear reducer is adopted to simulate the growth of wind turbine box, the growth rate is about 2.8.

Experimental platform to provide test of rolling bearing is bearing 307, a total of 2, only 1 fault 


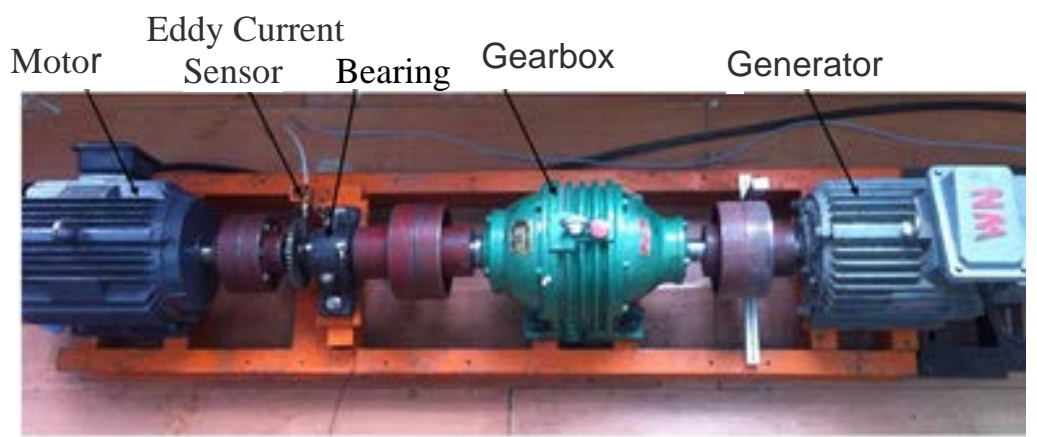

Fig.2 simulation platform

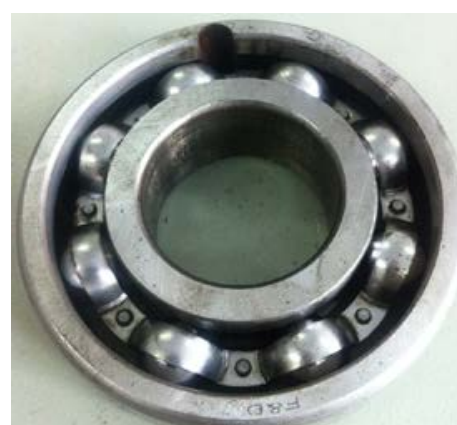

Fig.3 Bearing outer fault simulation

bearing, only 1 normal bearing. By making a small groove on the roll bearing to simulate roller bearing outer race fault, fault bearing shown in Figure 3.

\section{Analysis of experimental results}

Experiments analysis point at the outer ring fault of rolling bearing, research generator stator current signal characteristics when bearing is in different states. According to Hilbert transform demodulation principle, to capture the signal amplitude and frequency demodulation [6], then the spindle speed fluctuation signal corresponding comparative analysis.

Pick the generator excitation frequency $f_{2}=10 \mathrm{~Hz}$, the motor power supply frequency $f_{r 1}$ corresponding rotor speed is $42.2 \mathrm{rad} / \mathrm{s}$, the sampling frequency is $300 \mathrm{~Hz}$. According to collect generator stator current signal of bearing when it is in normal and fault condition, the calculated amplitude spectrum, amplitude envelope spectrum and instantaneous frequency spectrum as shown in Figure 4, 5.

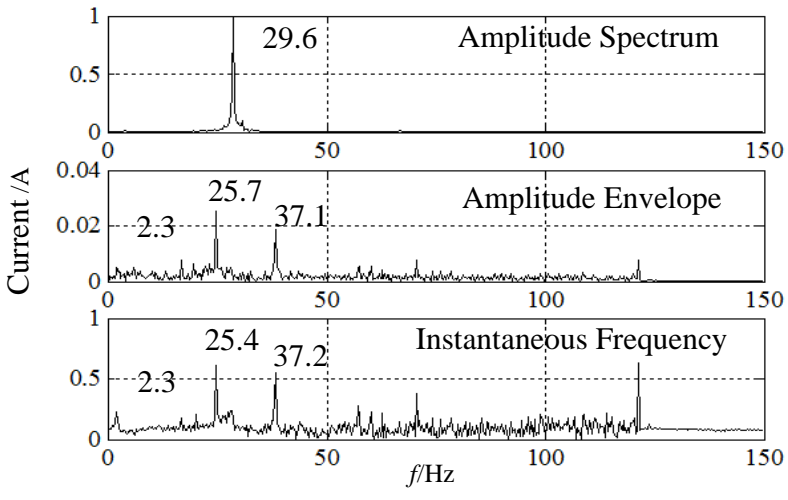

Fig.4 Stator current spectrum of normal bearing $\left(f_{2}=10 \mathrm{~Hz}, f_{r 1}=7.5 \mathrm{~Hz}\right)$

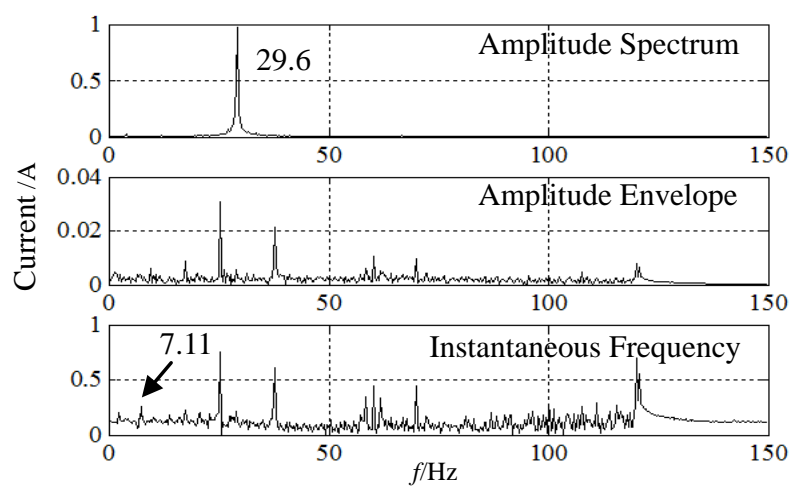

Fig.5 Stator current spectrum of fault bearing $\left(f_{2}=10 \mathrm{~Hz}, f_{r 1}=7.5 \mathrm{~Hz}\right)$

From Figure 4 and 5, when the rotor speed is $42.2 \mathrm{rad} / \mathrm{s}$ generated by the current signal frequency is $29.6 \mathrm{~Hz}$, in figure $4-1$, envelope spectrum and instantaneous frequency spectrum has obvious frequency components $2.3 \mathrm{~Hz} 、 25.7$ and $37.1 \mathrm{~Hz}, 2.3 \mathrm{~Hz}$ for the shaft rotational frequency reflect in the current spectrum, another $25.7 \mathrm{~Hz}, 37.1 \mathrm{~Hz}$ frequency components may cause the vibration of the gear box is reflected in the electrical signal, the two characteristic frequency will change with different speed, the other frequency components is not obvious.

To compare the bearing under normal and fault condition of electrical signal demodulation results, it is found characteristic frequency $7.11 \mathrm{~Hz}$ in the instantaneous frequency demodulation spectrum of fault bearing, but not find under normal condition, the frequency components of energy is weak but can be seen, this and through calculation of the proceeds of the outer ring fault characteristic frequency is roughly the same, it can determine the characteristic frequency of bearing outer ring fault frequency, no obvious changes in amplitude envelope spectrum.

In order to verify that the frequency is the fault characteristic frequency, but also collect the spindle rotation frequency signal to be compared. According to Eddy Current Transducers to collect signal of toothed plate, time domain and frequency domain waveform as shown in figure 6, figure 7. Figure 6 is a sampling frequency under the condition of the $f_{s}=300 \mathrm{~Hz}$ in normal bearing state, to 
observe the spindle speed fluctuation in the state. Figure 7 is a sampling frequency under the condition of the $f_{s}=300 \mathrm{~Hz}$ in normal bearing state, to observe the spindle speed fluctuation in the state, figure 7 shows that amplitude spectrum and amplitude envelope spectrum of spindle speed under fault bearing, when motor power supply frequency $f_{r}=7.5 \mathrm{~Hz}$ and the sampling frequency $f_{s}$ $=300 \mathrm{~Hz}$.

Figure 6 shows that two frequency component, $1.52 \mathrm{~Hz}$ and $62.3 \mathrm{~Hz}$, of which $1.52 \mathrm{~Hz}$ is the rotation frequency of the measured axis, $62.3 \mathrm{~Hz}$ for the eddy current displacement sensor by frequency of toothed plate (41 teeth). Because of the bearing fault caused the spindle speed fluctuation, by comparing the figure 6 and figure 7, you can see frequency components of $7.15 \mathrm{~Hz}$ caused by the velocity fluctuation in amplitude envelope spectrum, corresponding to the characteristic frequency $7.11 \mathrm{~Hz}$ demodulated by signal instantaneous frequency demodulation, it can be determined that the

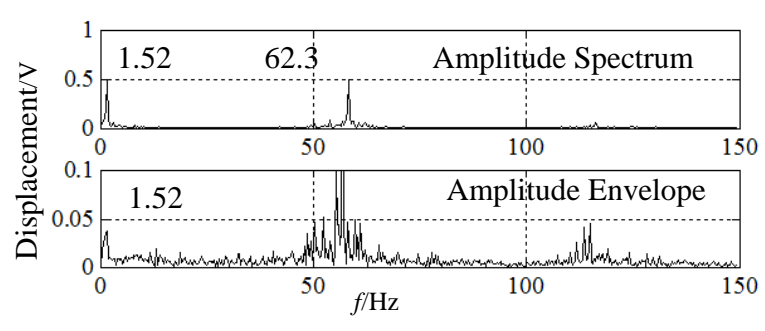

Fig.6 Speed fluctuation spectrum of main shaft of the normal bearing

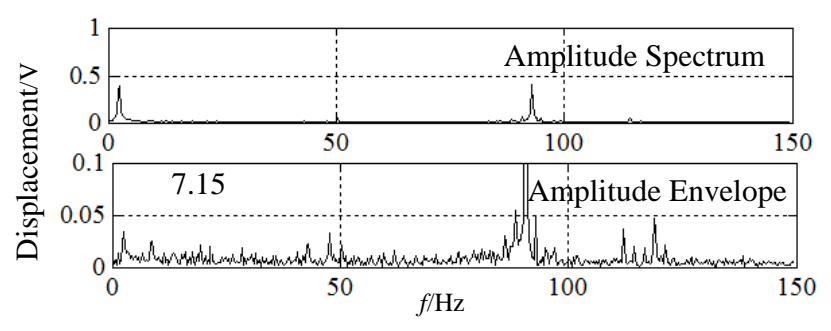

Fig.7 Speed fluctuation spectrum of the fault bearing $(\mathrm{fr} 1=7.5 \mathrm{~Hz})$

characteristic frequency is the frequency of bearing outer ring fault. There are some interference frequency components, which may be caused by the installation and equipment condition itself.

\section{Conclusion}

According to analyze the electrical signal and shaft's made by the generator bearing that works in normal and fault condition, the characteristic frequency of the fault signal can be seen from instantaneous frequency demodulation spectrum of the current signal, and Consistent with the characteristic frequency demodulated by spindle speed signal measured by the eddy current displacement sensor, at the same time, corresponding to mathematical theoretical model of the magnetic flux density effect on signal.

Therefore, according to the characteristics that fault will generate frequency modulation, wind turbine drive train rolling bearing fault signal can be diagnosed by demodulate current signal of generator.

\section{Acknowledgement}

This article comes from the National Natural Science Fund Project " Sensor-less fault diagnosis method research of wind turbine main drive chain"(Project No. 51275136).

\section{References}

[1] Kryter R C, Haynes H D. Condition monitoring of machinery using motor current signature analysis[J]. Sound and Vibration, 1999, 22(9): 1720-1725.

[2] HIROKIK, MINORUA, YASUOK, ET al.RoboCup: a challenge problem for AI and robotics. HirokiK. RoboCup-97: Robot Soccer World Cup [C]. Berlin: Springer, 1998.38-43.

[3] Zhizhong Yin. Application of FPGA control DC motor servo system [J]. Inner Mongolia Science and Technology and Economy, 2008177 (23) 101-103.

[4] Joerg Christian Wolf, Phil Hall, Paul Robinson, Phil Culverhouse. Bioloid based Humanoid Soccer Robot Design, 2007. 
[5] Wu Chuan yu, He Lei ying, Design and Realization of Instructional RPPR-Robot, Research and Exploration in Laboratory.2007, 26(10)

[6] Amirat Y. Choqueuse V. and Benbouzid M.E.H.. Wind Turbines Condition Monitoring and Fault Diagnosis Using Generator Current Amplitude Demodulation[C]. 2010 IEEE International Energy Conference and Exhibition, 2010:310-315. 